\title{
Models of addiction and types of interventions: An integrative look
}

\author{
Roland Simon $^{1}$ and Robert West ${ }^{2}$ \\ ${ }^{1}$ European Monitoring Centre for Drugs and Drug Addiction, Lisbon, Portugal \\ ${ }^{2}$ Cancer Research UK Health Behaviour Research Centre, Department of Epidemiology and Public Health, University College, London
}

\begin{abstract}
Background: Use of psychoactive substances and problem gambling create serious harm to individuals who engage in these practices and to society as a whole (World Health Organization, 2002). The European Monitoring Centre for Drugs and Drug Addiction (EMCDDA) regularly monitors drug-related problems and interventions, as well as the efficiency of interventions. The scope and methodology of monitoring, however, depends on the conceptualization of "addiction."
\end{abstract}

Methods: The relevant literature was screened for models and theories relating to "addiction," resulting in a systematic overview of the concepts and related approaches (EMCDDA, 2013). Using this as a background, different approaches for interventions and their theoretical bases are discussed.

Results: Models of addiction follow two approaches. Most of these focus on the individual addict, involving constructs such as emotions, drive states, habits, choice, and goal-oriented processes, or else taking a more integrative or change-oriented view. Others are population-based models, including social network, economic, communication, and organizational system models.

While substance- and non-substance-related addictions differ in a number of respects, they share key elements: a repeated powerful motivation to engage in a particular behavior, acquired through enacting the behavior, despite the experience or risk of significant harm. Nine different types of intervention to combat addiction found in the literature involve attempts to change one or more of three factors that interact to underpin behavior: capability, opportunity, and motivation (the "COM-B" model). The models of addiction reviewed may serve as a basis for such interventions.

Illicit psychoactive drug use, excessive alcohol consumption, tobacco use, and problem gambling create serious harm to individuals who engage in these practices and to society as a whole (World Health Organization, 2002). While not all substance-related harm arises from addiction, it clearly plays a major role. It is also apparent that today the concept of addiction seems not to be limited to illicit psychoactive drugs or indeed pharmacological agents. The European Monitoring Centre for Drugs and Drug Addiction (EMCDDA) has published two years ago an overview on models of addiction (2013), which aims to provide a clearer understanding of the nature of addiction. This in turn allows identification of factors that contribute to the development and maintenance of addiction. Interventions can target these factors in order to prevent, reduce, or stop addiction. Monitoring responses to drug problems should assess and follow up these different aspects to provide a full picture of responses towards drug problems in a society.

Based on the aforementioned overview, this paper reviews the main models specific to addiction, as well as more general ones that were used, starting from a comprehensive mapping of the concept in scientific literature. What constitutes a "model" is interpreted here quite broadly and includes general theoretical approaches and specific theories.

Following the review of models, an integrative approach is used to describe the core elements of these models and to give an overview on general approaches used in prevention and treatment derived from them. While social responses to drugs and drug use include measures of supply reduction as well as demand reduction, the concept of "addiction” is discussed here mainly from a health perspective.

\section{Method}

Based on a first literature search on "addiction" and “dependence” (National Institute on Drug Abuse, 2011; Padwa \& Cunningham, 2010) the following working definition of addiction was chosen as a starting point: "a repeated powerful motivation to engage in a purposeful behavior that has no survival value, acquired as a result of engaging in that behavior, with significant potential for unintended harm.” 
In order to gain a comprehensive mapping of the main models of addiction in scientific publications, a systematic literature search was conducted using Web of Science and Google Scholar. While the terms "theory" and "model" are often used interchangeably, theories are explanatory while models can also be purely descriptive. What constitutes a model is interpreted here quite broadly in order to encompass broad conceptual frameworks as well as specific coherent accounts. To cover both elements under the umbrella term of "models" the following search terms were used: "(addiction or dependence or alcohol or nicotine or smok* or tobacco or cannabis or gambling or opiat* or stimulan*) and (theory or theories).”

There may be models specific to other addictive behaviors (e.g., Internet games) but the behaviors identified through our search are thought to cover the core addictions that are widely recognized as such. Sources included in this search were articles, books, reports, and book chapters. Summaries and abstracts were used to identify theories or models. In addition, experts in the field were consulted and theories reported by them were added if these had not previously been identified. The approach taken in this review was to attempt to extract key ideas from both explicit theories and theoretical ideas not explicitly labeled as theories, and to classify them using an updated version of the system adopted in West (2006).

Some descriptions of models found were very general and involve little more than a statement of an approach or orientation, whereas others were very specific. Theories may be described slightly differently across the accounts of various sources, differ in their formulations, or evolve over time. Some theories are clearly labeled as such, whereas others express theoretical ideas without explicitly labeling them as theories. The review also included theories that had been, or could be, applied to addiction, even if they were not specifically developed for that purpose. All in all, this review has been broadly inclusive to allow a wide variety of models to be collected and integrated in the analysis.

\section{The Classification System}

The classification system presented here has been in development since 2006 using an iterative process of drafting, discussion with colleagues, and redrafting. Where a model could have been classified under different headers, the choice was made in accordance with what appeared to be the dominant feature of the theory. Where conceptual overlaps between models exist, we focused on the specific characteristics of each model.

Addiction is understood as a behavioral concept, reflecting a broad scope of models found in the literature. This approach was thought to both include and value quite different theoretical concepts without making an a priori judgment. A definition of addiction, for example, as a brain disease (Leshner, 1997), might have set a hierarchy of relevance for models that could have limited an open discussion of all concepts found.

The classification system that resulted from this collection and analysis clearly is not the only classification that could be adopted and it involves a number of compromises. It does not follow a neat hierarchy but has some element of hierarchical structure. Some of the theories could be located in more than one category and a certain level of arbitrariness could not always be avoided. For example, a model put under "goal-focused theories" might have also be put under "learning theories". The choice of labels (e.g., "rational" or "biased" choice) is purely descriptive and should not indicate the quality of different models.

\section{The Main Concepts of Addiction}

Numerous mechanisms underlying addiction have been discovered and these have spawned a multitude of models, each of which addresses a part of the problem. A large number of models of addiction have been proposed that describe these mechanisms. While no neat hierarchical classification could be found to integrate all these models for heuristic purposes, they can be classified in terms of whether they focus on individuals or populations. This approach seems appropriate as it reflects the two general approaches available when society wants to respond to addiction-either through prevention and treatment focusing on the individual or through changing conditions (availability, acceptance) at the population level.

An overview of the classification is provided in Figure 1, while more details per model can be found below.

Different groups of models are described below. Some individual models are presented as examples without assuming that they would be the most representative of their group, as the variety of models that exist make such a choice impossible. Implications for interventions are discussed at the end of each group of models.

\section{Modeling the Individual Addict}

In this group of models, addiction arises out of individual characteristics - either pre-existing or acquired-which, interacting with a given set of environmental circumstances, result in powerful motivations to engage in potentially harmful behavior patterns. The majority of models found have been classified under this category with respective groups of models as follows.

1. Automatic processing theories assume that behaviors are shaped without the need for conscious decisions or intentions, and/or the influence of our capacity for self-regulation. The following subgroups are included: (a) learning theories that assume addiction involves learning of associations between cues, responses, and powerful positive or negative reinforcers; (b) drive theories linking addiction to homeostatic mechanisms that constitute powerful motivations. "Craving" is a core concept here; (c) inhibition dysfunction theories, which claim that in addiction those mechanisms usually in place to control impulses are impaired, at least as regards the addictive behavior; (d) imitation of behavior leading to addiction. Examples for this group of models include operant conditioning (Mook, 1995); craving (Jellinik, 1960), and social learning (Bandura, 1977). 
Figure 1

\section{Classification of models of addiction} Addiction theories

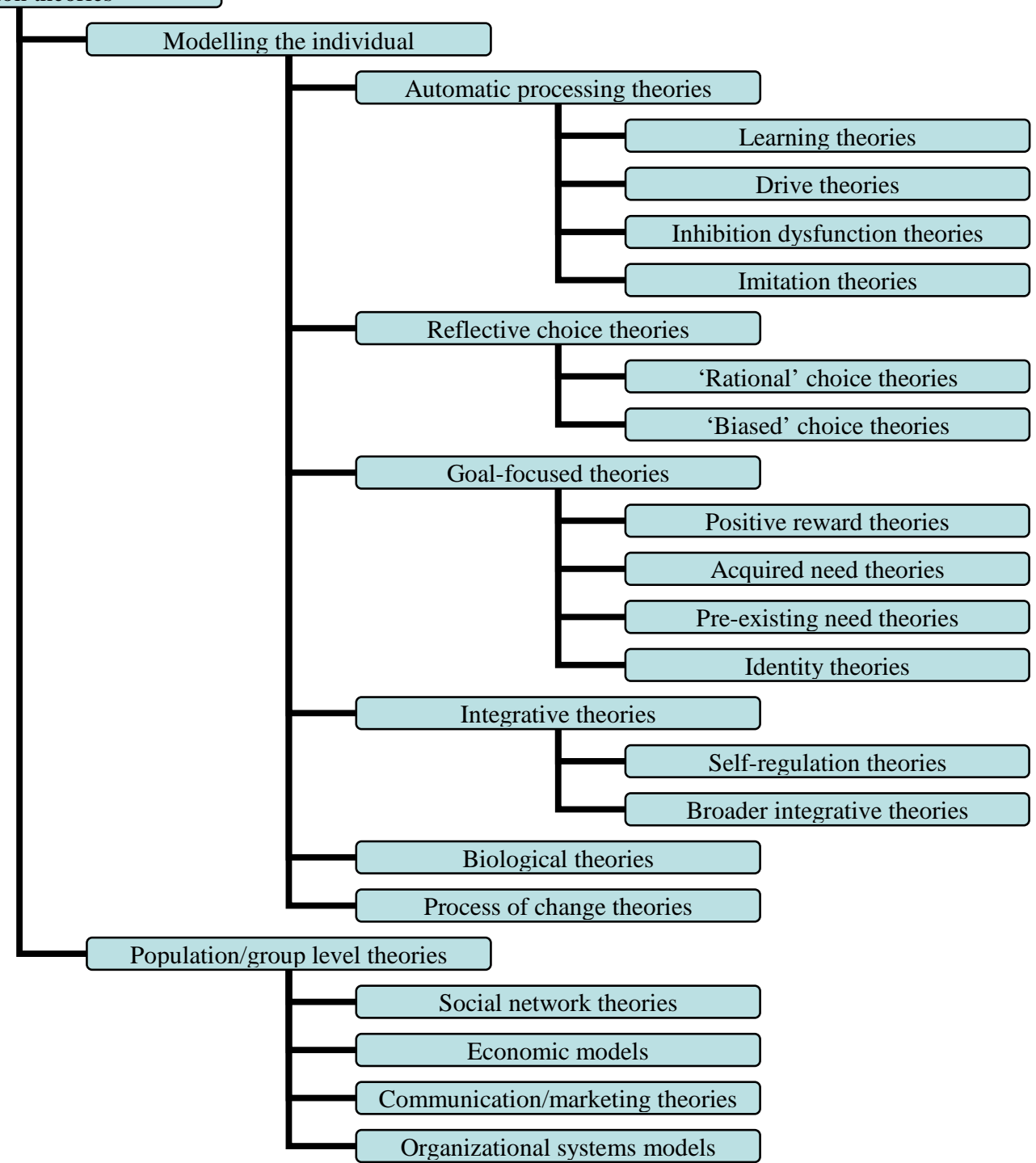

As a consequence of these kinds of model, prevention or treatment is conceptually based on learning alternative behaviors, increasing control or decreasing strength of addictive behaviors, and avoiding cues and/or triggering stimuli for addictive behaviors. Training and repetition of new associations are often important for positive change under this model rather than changes in beliefs or insight. Medication can be used to block reinforcing actions and to support the process of change.

2. Reflective choice theories are based on the notion that human behavior is — at least in parts_-governed by a self-conscious analysis of options and decision-making on alternatives. The (a) "rational" choice group of models assumes that addiction is the result of a rational choice where perceived benefits would outweigh costs. The preference for the addictive behavior may reflect an extremely highly valued positive effect of this behavior, which outweighs in the individual's choice its negative consequences. The group of (b) "biased" choice theories assumes that an individual is making a reflective choice but experiences the effects of emotional, temporal (temporal discounting), or other factors that reduce the quality of the process and may result in maladaptive choices. Examples for this group of models include rational addiction (Becker \& Murphy, 1988), positive and negative expectancies (Jones, Corbin, \& Fromme, 2001), and 
temporal discounting (Ainslie \& Monterosso, 2003).

Prevention and treatment from this perspective try to change the benefit/cost ratio by increasing the cost of addictive behavior and/or increasing benefits from non-addictive behavior, to influence the perception of this ratio accordingly, or to mitigate the effect of irrational influences in making such choices.

3. Goal-focused theories focus mainly on the goal of addictive behaviors. In the subgroup of a) positive reward theories, the pleasure and satisfaction that arises from addictive behaviors is the major driving force. This could be physiologically produced euphoria but also could be objectives such as a perfect body shape (through weight control or smoking). (b) Acquired need theories start from the positive and rewarding physiological effects of addictive substances, which lead through repeated use to habituation and adaptation. The effects of withdrawal from repeated use are then-as acquired or secondary needs - tackled through addictive behavior again. (c) Some addicts may have specific pre-existing needs that considerably contribute to their addictive behavior, possibly a particular vulnerability or past traumatic experiences. The resulting psychological needs contribute to the process of reflective choice again. (d) Identity and identification can be a driving force behind addictive behaviors-for example, when selfdestructive or antisocial elements are present. Examples for this group of models include weight control theory of tobacco smoking (Kanayama, Brower, Wood, Hudson, \& Pope, Jr., 2009), opponent-process theory (Solomon, 1980), and selfaffirmation theory (Harris, Mayle, Mabbott, \& Napper, 2007).

From the perspective of goal-focused theories, the motor behind addiction is seeking pleasure or, more generally, wanting to meet needs. Thus interventions should try to reduce pleasure through addictive behavior-for example, by improving the level of internal control through medication, or by helping to develop alternative sources of pleasure and fulfillment.

4. Integrative theories combine the different elements mentioned above. They assume that environmental aspects and internal states and traits are important factors, which interact with automatic or conscious processes targeting pleasure or the avoidance of discomfort. (a) Self-regulation theories focus on an individual's ability to counter immediate reactions towards impulses and desires. This ability can be insufficient due to a lack of strategies, skills, or capacity. (b) A number of theories are even broader in concept, combining individual traits and behaviors with environment and social context and a number of different processes. These theories try to overcome the limitations of more specific models by integrating all factors of influence in one model. Examples for this group of models include cognitive control theory (Miller \& Cohen, 2001), excessive appetites theory (Orford, 2001), and PRIME theory (West \& Sohal, 2006).

Due to the broad scope of integrative theories, approaches towards prevention and treatment can make reference to most of the options listed for the more specific models. In this respect, integrative theories are more eclectic and inclusive than specific models.

5. In biological theories, addiction is conceptualized as a "brain disease," assuming that neural functioning in addicts differs from non-addicts. Many factors are thought to influence this process, including substance use and its physiological effects, environmental factors, and genetics. As human behavior is closely associated with brain activities, all these factors are thought to contribute to addiction, mainly through their neural effects. In this area, micro-theories focus on basic mechanisms. One could mention here the concept of neural circuitry in addiction (Brewer \& Potenza, 2008) or discussions on the role of dopamine (Volkow, Fowler, \& Wang, 2002).

As many of the most impressive findings in the field of neuroscience are relatively new, science is still more focused on the basic mechanisms in these models while more applied research, especially around prevention and treatment, is scarce. There is a clear and increasingly strong link with prevention research, but biological theories would clearly also point to pharmaceutical treatment and other possible ways to change the way in which an addicted brain functions. More research will be needed before these models are able to provide concepts for practical interventions.

6. While process of change theories also refer to the individual, they clearly differ from the models listed before by focusing directly on how people recover from addiction, while most of the other models try to explain how and why addiction develops. Process of change models try to optimize interventions based on a general step-by-step model of change for attitudes and behaviors. Interventions from this perspective are in some cases adapted to the appropriate "stage" in order to maximize effect. One of the strengths of these theories is their ability to conceptually include relapse-seen as one phase in the decision-making process - which might be experienced multiple times. Examples for this group of models include cognitive dissonance theory (Festinger, 1957), the transtheoretical model (Prochaska, Diclemente, \& Norcross, 1992), and the relapse prevention model (Marlatt \& George, 1984). 
For prevention and treatment, the main conclusion from these theories would be to use interventions that specifically reflect the user's state in decisionmaking. The intervention should be tailored to the stage or state of change and/or the specific relapse process operating within the individual or his or her environment.

\section{Modeling populations}

The term "drug epidemic" has been used frequently in the public debate on drug policy to describe the driving role of social networks in the spread of drug use. "Infection" through social exchange seems to stand as a transmission process behind this lay concept-similar to the spread of infectious diseases through virus or bacteria. Following a similar line of reasoning, the group of models analyzed here are assuming that addictive behavior develops within and through populations and tries to understand addiction in terms of the interplay between population-level parameters. The following groups of models can be found here.

1. Social network theories: These models see transitions of individuals into and out of addiction as group processes, defined by social connections between individuals that have positive of negative positions towards addictive behaviors. Core elements in these models are concepts explaining the construction of social groups, the spread of new behavior within such groups and the role of individual choices versus following the group norms. Examples for this group of models include diffusion theory (Ferrence, 2001) and actor-network theory (Young, Borland, \& Coghill, 2011).

Implications of these models for prevention and treatment are as follows: social connections should be selectively strengthened or weakened depending on the position the other person takes with respect to addictive behaviors. Other approaches include influencing group opinion through information or mobilization in order to affect individual behavior through group norms.

2. Economic models assume that addictive behaviors in populations can be predicted by functions from economic theory, including financial and other costs, availability of the behavior, and competing/alternative behaviors. These models are mainly interesting for legal addictive substances where these parameters can be influenced through policy decisions: taxation can change the price of alcohol, and legal restrictions can increase the costs to the individual and influence addictive behavior in that way. Under conditions of illicit markets, legal restrictions are high by definition and policy has limited means to steer behavior in more specific ways. They also facilitate comparing different policy approaches by providing a sound basis for calculating the costs and gains for different options. Examples for this group of models include price elasticity (John, 2008) and cross-elasticity models (Mytton, Gray, Rayner, \& Rutter, 2007).

The application of such models is relatively straightforward and can be seen in approaches to tobacco taxation in recent years in most Western European countries and elsewhere. At the same time, intervention costs can be calculated and the overall economic effect of different options compared. Behavioral aspects of contingency management are conceptually close to these models.

3. Communication/marketing models see the addict as a consumer and assume that persuasive communication and marketing activities will have a considerable influence on the development of addictive behavior. This is in general more openly visible around alcohol, gambling, and other legal substances and addictive behaviors. But to some extent, illicit drugs are also marketed. No specific theory was found here, but reference is made to contemporary marketing theory as a whole.

The main focus of interventions from this perspective is to weaken the possible effects of marketing activities that increase addictive behavior through bans of certain products and/or activities. This approach has been highly relevant in recent years in the Western world in reducing tobacco smoking in the population.

4. Organizational systems models look at addictive behavior in terms of systems where social components (e.g., government and public) interact in a complex way. Effects of innovation in such a system might be nullified by compensatory changes and besides the influence of each element, the effect of its interaction has to be considered. Examples for this group of models include the tobacco use management system (Borland, Young, Coghill, \& Zhang, 2010).

These models imply that a thorough understanding of the mutual dependencies and interactions of different parts of the system is needed in order to have an impact on the system overall. If interventions are well chosen, they might cause a positive chain reaction; otherwise effects might be nullified through counterbalancing alternative factors of influence.

\section{Models as basis for interventions}

A considerable number of models have attempted to explain how addiction develops, how it is maintained, and how people could recover from it. While none of the theories today is accepted as the integrative single model of addiction, in conjunction the models provide us with a wide understanding of the concept. Commonalities and overlaps in definition and concept are mirrored by positive correlations found between, for example, alcohol and nicotine addiction or heroin and cocaine addiction, as well 
as by similarities in etiology, risk, and protective factors found for different substances and non-substance-related forms of addiction.

While we lack a model that would include all aspects listed above, we do find the major common elements combined in integrative concepts, such as the COM-B model. This model is based on a concept of behavior (and respective behavior change) which can help to structure intervention in a more systematic way, starting from three core factors underpinning behavior: (a) capability: the individual physical or psychological skills and capacity to engage and steer an action; (b) opportunity: environmental factors that make a behavior possible and may facilitate or hinder it; including physical and social factors; and (c) motivation: referring to the internal processes with energize and steer behavior based on reflective and/or automatized processes (Michie, van Stralen, \& West, 2011b). Linked to this model, Michie et al. (2011b) have recently provided a classification of approaches for behavior change. In our report, we have combined models, factors of behavior, and interventions in an attempt to provide a systematic overview of this complex matter. Models were listed under those factors and interventions where conceptual links seemed to be most clear. However, a considerable amount of uncertainty remains and some models could also be placed elsewhere. A number of models can be attributed to different types of interventions and are listed therefore several times in the table (Table 1 ).

\section{Table 1}

Factors of behavior, models of addiction, and types of intervention

\begin{tabular}{|c|c|c|c|c|}
\hline \multirow{2}{*}{$\begin{array}{l}\text { Factors of } \\
\text { Behavior }\end{array}$} & \multirow{2}{*}{$\begin{array}{l}\text { Models of } \\
\text { Addiction }\end{array}$} & \multicolumn{3}{|c|}{ Type of Intervention } \\
\hline & & Name & Definition & Examples \\
\hline \multirow[t]{2}{*}{ Opportunity } & $\mathrm{P} 2$ & Restriction & $\begin{array}{l}\text { Using rules to influence the } \\
\text { opportunity to engage in the target } \\
\text { behavior }\end{array}$ & $\begin{array}{l}\text { Controlling the supply of opiate } \\
\text { medications }\end{array}$ \\
\hline & $\mathrm{P} 2$ & Environmental restructuring & $\begin{array}{l}\text { Changing the physical or social } \\
\text { context }\end{array}$ & $\begin{array}{l}\text { Limiting the number of alcohol } \\
\text { outlets in a district }\end{array}$ \\
\hline \multirow[t]{13}{*}{ Motivation } & $\mathrm{I} 1$ & \multirow[t]{3}{*}{ Modeling } & \multirow{3}{*}{$\begin{array}{l}\text { Providing an example for people to } \\
\text { aspire to or imitate }\end{array}$} & \multirow{3}{*}{$\begin{array}{l}\text { Showing a popular media } \\
\text { personality successfully battling } \\
\text { against alcohol addiction }\end{array}$} \\
\hline & I3 & & & \\
\hline & $\mathrm{P} 1$ & & & \\
\hline & $\mathrm{I} 1$ & \multirow[t]{3}{*}{ Persuasion } & \multirow{3}{*}{$\begin{array}{l}\text { Using communication to induce } \\
\text { positive or negative feelings or } \\
\text { stimulate action }\end{array}$} & \multirow{3}{*}{$\begin{array}{l}\text { Using imagery to create a feeling of } \\
\text { disgust at the effects of smoking }\end{array}$} \\
\hline & I6 & & & \\
\hline & P3 & & & \\
\hline & $\mathrm{I} 1$ & \multirow[t]{5}{*}{ Incentivization } & \multirow[t]{5}{*}{ Creating expectation of reward } & \multirow{5}{*}{$\begin{array}{l}\text { Using financial incentives to } \\
\text { promote abstinence from cocaine }\end{array}$} \\
\hline & $\mathrm{I} 2$ & & & \\
\hline & I3 & & & \\
\hline & I5 & & & \\
\hline & I6 & & & \\
\hline & I3 & \multirow[t]{2}{*}{ Coercion } & \multirow{2}{*}{$\begin{array}{l}\text { Creating expectation of punishment } \\
\text { or cost }\end{array}$} & \multirow[t]{2}{*}{ Raising the price of alcohol } \\
\hline & $\mathrm{P} 2$ & & & \\
\hline \multirow[t]{4}{*}{ Capability } & $\mathrm{I} 1$ & \multirow[t]{3}{*}{ Education } & \multirow{3}{*}{$\begin{array}{l}\text { Increasing knowledge or } \\
\text { understanding }\end{array}$} & \multirow{3}{*}{$\begin{array}{l}\text { Informing smokers about optimal } \\
\text { methods of quitting }\end{array}$} \\
\hline & $\mathrm{I} 2$ & & & \\
\hline & I6 & & & \\
\hline & P4 & Training & Imparting skills & $\begin{array}{l}\text { Training bar staff in skills to refuse } \\
\text { to serve intoxicated patrons }\end{array}$ \\
\hline \multirow{2}{*}{$\begin{array}{l}\text { Opportunity } \\
\text { Motivation } \\
\text { Capability }\end{array}$} & I4 & \multirow[t]{2}{*}{ Enablement } & \multirow{2}{*}{$\begin{array}{l}\text { Increasing means/ reducing barriers } \\
\text { to increase capability or opportunity }\end{array}$} & \multirow{2}{*}{$\begin{array}{l}\text { Provision of buprenorphine or } \\
\text { methadone to help addict limit } \\
\text { heroin use }\end{array}$} \\
\hline & P4 & & & \\
\hline
\end{tabular}

Note: I: Individual-based models

P: Population-based models

Table based on Mitchie et al. (2011a; 2011b) 
Nine different types of interventions ("intervention functions") result from the analysis made by Michie et al. (2011a; 2011b). Two of them target opportunity and capability respectively; four of them are focus mainly on motivation. One type of intervention (enablement) targets all three aspects at once.

As the overview shows, most of the individual-based models are related to motivation as a factor of behavior and to modeling, persuasion, and incentivization as type of interventions. Some of the individual-based models also show a link to development of capabilities through education. Conversely, population-based models are the main concepts behind interventions influencing opportunity (i.e., restriction and environmental restructuring). But they can also be linked to the behavioral factor of motivation: here interventions at population level may function via their effects on the motivation and capability of drug users and others. Enablement as an intervention targets all factors at the same time with a clear link to population models. Process of change theories (I6) can serve as a theoretical base for a number of interventions when it comes to the question of timing. By definition, integrative theories (I4) target all aspects of behavior and can be linked to most of the interventions listed. Biological theories (I5) can to some extent also be linked to all interventions; however, they mainly target motivation and capability.

\section{Discussion}

This analysis of models of addiction is based on a theorydriven perspective and started from a broad overview of existing concepts and theories on addiction. The resulting classification helps to understand the broad variations of views but also shows integrative approaches. A number of limitations have to be mentioned here.

The result of this analysis is mainly descriptive. The different models are put in a common framework, but we have not tried to judge the adequacy or usefulness of the models. Some reference on the evidence found can be found elsewhere (EMCDDA, 2013). We came across no single generally accepted model.

The development of the classification system was driven by Robert West and his colleagues over many years in a stepby-step iterative process that included numerous discussions between different experts and stakeholders. By definition, such a process does not follow a clearly defined method but is based on a process of repeated drafting, critical discussion, and redrafting. While this process will continue, the system presented here already enables us to view and understand the different approaches science has taken towards addiction and related interventions. It is clear that this is just one way of structuring the field.

As we are not in a position, and may never be, to present one model and one approach to combating addiction as the gold standard, it seems sensible to make use of the variety of approaches found, carefully considering the evidence of effectiveness that exists when we apply them. One might also wonder if all models of addiction have been exploited in depth, in order to develop promising approaches for interventions. While the number of models targeting motivation seems quite impressive, other behavioral factors have been less well exploited.

One can find a number of specific elements when looking into models of addiction for licit and illicit psychoactive substances and substance- and non-substance-related addictive behaviors. But they have some elements in common. They all talk about a repeated, powerful motivation to engage in a particular behavior, acquired through enacting the behavior, despite the experience or risk of significant harm. These commonalities seem to be broad enough to continue studying addiction as a topic of general interest by itself.

\section{References}

Ainslie, G., \& Monterosso, J. (2003). Hyperbolic discounting as a factor in addiction: A critical analysis. In R. E. Vuchinich, \& N. Heather (Eds.), Choice, behavioural economics and addiction. Amsterdam, The Netherlands: Pergamon.

Bandura, A. (1977). Self-efficacy: Toward a unifying theory of behavioural change. Psychological Review, 84, 191-215.

Becker, G. S., \& Murphy, K. M. (1988). A theory of rational addiction. Journal of Political Economy, 96, 675-700.

Borland, R., Young, D., Coghill, K., \& Zhang, J. Y. (2010). The tobacco use management system: Analyzing tobacco control from a systems perspective. American Journal of Public Health, 100, 1229-1236.

Brewer, J. A., \& Potenza, M. N. (2008). The neurobiology and genetics of impulse control disorders: Relationships to drug addictions. Biochemical Pharmacology, 75, 63-75.

European Monitoring Centre for Drugs and Drug Addiction (EMCDDA). (2013). Models of addiction: EMCDDA Insight Series No 14. Luxembourg: Publications Office of the European Union.

Ferrence, R. (2001). Diffusion theory and drug use. Addiction, 96, 165-173.

Festinger, L. (1957). A theory of cognitive dissonance. Standford, CA, United States: Stanford University Press.

Harris, P. R., Mayle, K., Mabbott, L., \& Napper, L. (2007). Self-affirmation reduces smokers' defensiveness to graphic on-pack cigarette warning labels. Health Psychology, 26, 437-446.

Jellinek, E. M. (1960). The disease concept of alcoholism. New Brunswick, NJ, United States: Hillhouse Press.

John, R. M. (2008). Price elasticity estimates for tobacco products in India. Health Policy and Planning, 23, 200-209.

Jones, B. T., Corbin, W., \& Fromme, K. (2001). A review of expectancy theory and alcohol. Addiction, 96, 5772.

Kanayama, G., Brower, K. J., Wood, R. I., Hudson, J. I., \& Pope, H. G., Jr. (2009). Anabolic-androgenic steroid 
dependence: An emerging disorder. Addiction, 104, 1966-1978.

Leshner, A. I. (1997). Addiction is a brain disease, and it matters. Science, 278, 45-47.

Marlatt, G. A., \& George, W. H. (1984). Relapse prevention: Introduction and overview of the model. British Journal of Addiction, 79, 261-273.

Michie, S., Ashford, S., Sniehotta, F. F., Dombrowski, S. U., Bishop, A., \& French, D. P. (2011a). A refined taxonomy of behaviour change techniques to help people change their physical activity and healthy eating behaviours: The CALO-RE taxonomy. Psychology and Health, 26, 1479-1498.

Michie, S., van Stralen, M. M., \& West, R. (2011b). The behaviour change wheel: A new method for characterising and designing behaviour change interventions. Implementation Science, 6, 42.

Miller, E. K., \& Cohen, J. D. (2001). An integrative theory of prefrontal cortex function. Annual Review of Neuroscience, 24, 167-202.

Mook, D. (1995). Motivation: The organization of action. London, England: Norton.

Mytton, O., Gray, A., Rayner, M., \& Rutter, H. (2007). Could targeted food taxes improve health? Journal of Epidemiology and Community Health, 61, 689-694.

National Institute on Drug Abuse. (2011). Understanding drug abuse and addiction. Retrieved from http://www.drugabuse.gov/publications/drugfacts/und erstanding-drug-abuse-addiction

Orford, J. (2001). Addiction as excessive appetite. Addiction, 96, 15-31.

Padwa, H., \& Cunningham, J. (2010). Addiction: A reference encyclopaedia. Santa Barbara, CA, United States: Greenwood Publishing Group.

Prochaska, J. O., Diclemente, C. C., \& Norcross, J. C. (1992). In search of how people change: Applications to addictive behaviors. American Psychologist, 47, 1102-1114.

Solomon, R. L. (1980). The opponent-process theory of acquired motivation: The costs of pleasure and the benefits of pain. American Psychologist, 35, 691-712.

Volkow, N. D., Fowler, J. S., \& Wang, G. J. (2002). Role of dopamine in drug reinforcement and addiction in humans: Results from imaging studies. Behavioural Pharmacology, 13, 355-366.

West, R. (2006). Theory of addiction. Oxford, England: Wiley-Blackwell.

West, R., \& Sohal, T. (2006). "Catastrophic" pathways to smoking cessation: Findings from national survey. The BMJ Clinical Research, 332, 458-460.

World Health Organization. (2002). The World Health report 2002. Geneva, Switzerland: World Health Organization.

Young, D., Borland, R., \& Coghill, K. (2011). An actornetwork theory analysis of policy innovation for smoke-free places: Understanding change in complex systems. American Journal of Public Health, 100, 1208-1217. 